\title{
Moroccan Agoudal Impact Crater: Allochthonous or Autochthonous Shatter Cones Origin?
}

\author{
Abderrahmane Ibhi", Hassane Nachit \\ Geoheritage and Geomaterials Laboratory, Faculty of Sciences, B.P. 8106, University of Ibn Zohr, Agadir, Morocco \\ *Corresponding Author: a.ibhi@uiz.ac.ma
}

Copyright (c) 2013 Horizon Research Publishing All rights reserved.

\begin{abstract}
A small eroded impact crater was recognized at about $20 \mathrm{~km}$ to the south of Isli impact carter (Central High Atlas, Morocco) at (31 $\left.59^{\prime} 12.7^{\prime \prime} \mathrm{N} ; 5^{\circ} 30^{\prime} 57.3^{\prime \prime} \mathrm{W}\right)$. The crater had been recognized through the presence of shatter cones. Very beautiful shatter cones have been found in samples of Jurassic limestone. The mapping of 40 individual shatter cones revealed an area of at least $1 \mathrm{~km}^{2}$ covered by these features. The shatter cones are not in place because they are harvested in Jurassic limestone wrapped in quaternary deposits, predominantly at the flanks of the dry rivers, They Are not observed in the bedrock. While many shatter cones displayed curved and spoon-like surfaces, many are also conical with apices pointing in opposite directions. Complete Cones are present only in $10-15 \%$ of the samples studied. The discovery indicates the presence of unknown, deeply eroded impact structure or only they are ejected of nearby impact crater.
\end{abstract}

Keywords Meteorites, Impact crater, Shatter cones, Agoudal, Imilchil, Morocco.

\section{Introduction}

The work of Ibhi et al. [1] showed, that the Isli lake in Central High Atlas, Morocco at $65 \mathrm{~km}$ north of the Tighir city $\left(32^{\circ} 13^{\prime} \mathrm{N} ; 05^{\circ} 38^{\prime} \mathrm{W}\right)$ is the result of a meteorite fall 40.000 years ago. In the location of Agoudal at $22 \mathrm{~km}$ to the south of Isli lake Sadilenko et al. [2] mentioned the presence of a small impact crater located at the coordinates $\left(31^{\circ} 59^{\prime} 12.7^{\prime \prime} \mathrm{N} ; 5^{\circ} 30^{\prime} 57.3^{\prime \prime} \mathrm{W}\right)$. These two structures are situated on a north-south axis. During the June 2013 we carried out again a field survey in the area, which led to new discoveries of shatter cones about $20 \mathrm{~km}$ in the south of the Isli structure (figure 1). They are abundant and well developed in Agoudal, due in to the abundance of fine-grained carbonates in the target sequence. Shatter cones are one of the most characteristic products of hypervelocity impact events and are the only shock metamorphic effect that develop on a megascopic scale $[3,4]$. Despite the recognition of shatter cones in dozens of terrestrial impact structures, there is still considerable uncertainty concerning their mechanisms of formation. In this preliminary study, we will discuss the different types of chatter cones found in the Agoudal locality and their allochthonous or autochthonous origins.

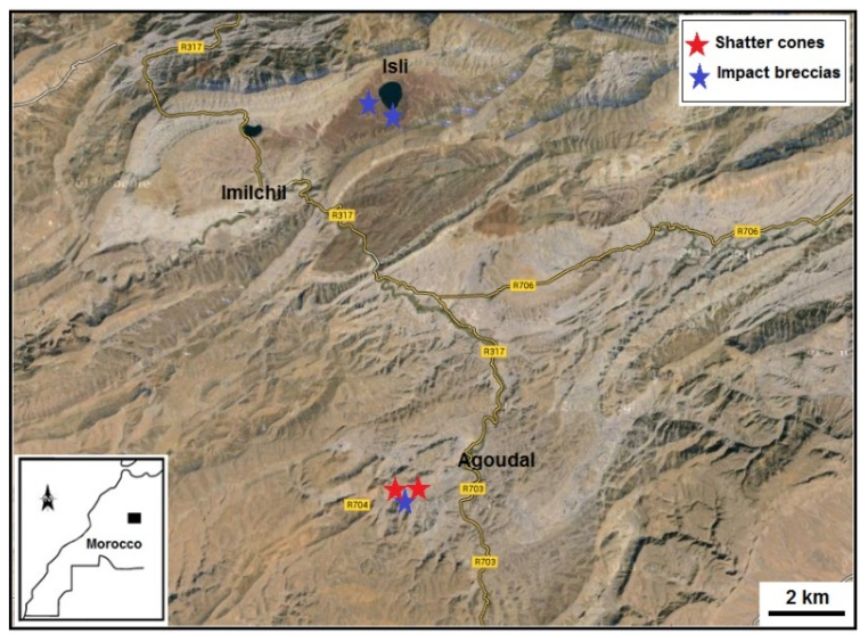

Figure 1. T opographic map showing the location of shatter cones and impact breccias in the Imilchil and Agoudal area. (Google earth) 


\section{New Observations}

\subsection{Impact craters}

The Isli crater [1] is an almost regular bowl with very pronounced slopes. Its maximum depth is 95 meters and the measured seismic profiles revealed that the thickness of sediments filling the lake is about 100 meters, where the oldest ones have an age of about 40000 years [5]. The sedimentary formations that are almost tabular at the platform of the lake become inclined with centripetal dips, all around towards the Isli lake forming thus its watershed.

Polymict and monomict breccias were observed at the edges of these craters. They don't form big masses, and the erosion has probably erased most of them. They consist of irregular fragments with millimeter and centimeter sizes in a carbonate matrix. In the breccias collected on the southern edges of the Isli crater we noted the presence of several shocked quartz grains with planar structures (PF) [6,7] associated sometimes with rolling extinction (figure 2), which are indicators of shock metamorphism. We also have been able to observe radial fractures which could have been generated by impacts [8].
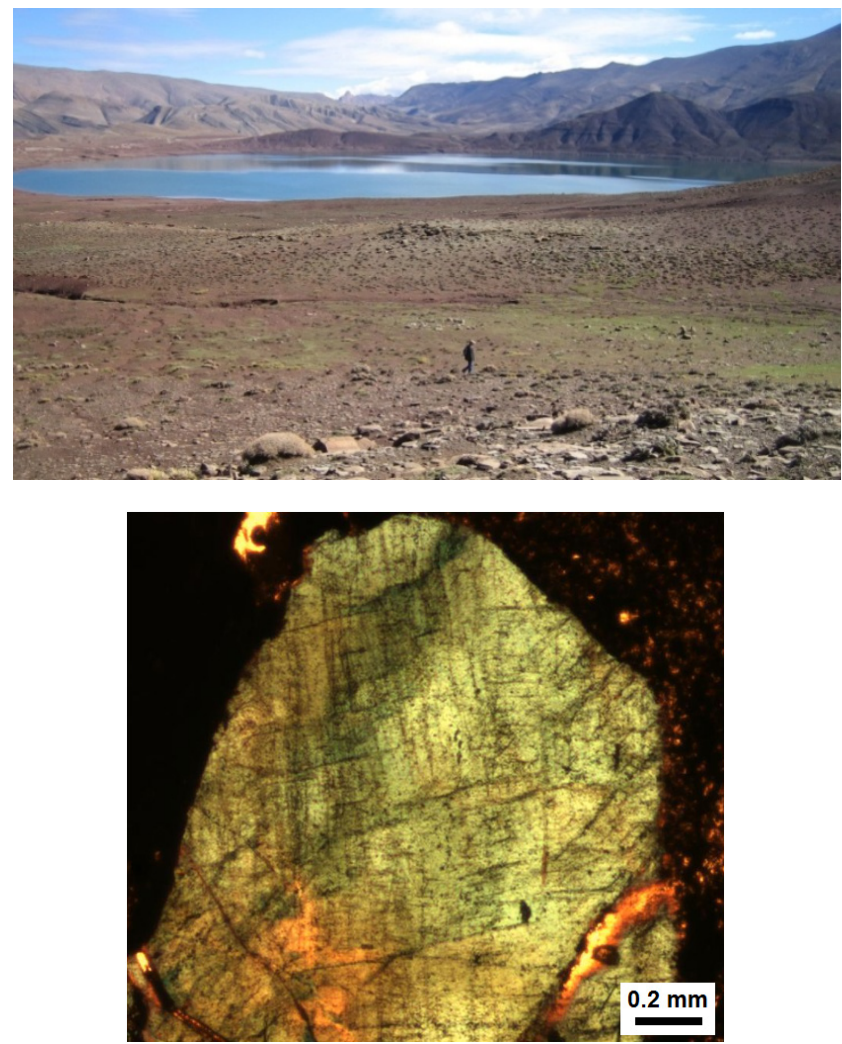

Figure 2. Isli crater and shocked quartz showing PFs

A small eroded impact crater was recognized at about 22 $\mathrm{km}$ to the south of the Isli Lake at the following coordinates $\left(31^{\circ} 59^{\prime} 12.7^{\prime \prime} \mathrm{N} ; \quad 5^{\circ} 30^{\prime} 57.3^{\prime \prime} \mathrm{W}\right)$. The crater has been recognized through the presence of shatter cones [2]. Our investigation on the terrain showed us, that the location of the crater corresponds to the flank of a syncline with a dip of $25^{\circ}$ to the north. Its shape cannot be defined because of a lack of a visible rim or something else which would distinguish it from the surrounding facies. Additionally, the whole north-western part of the synclinal flank, where the crater is located, is washed out by a big valley with a width of $300 \mathrm{~m}$. However very beautiful shatter cones (figure 3) have been found in samples of Jurassic limestone wrapped in quaternary deposits, predominantly at the flanks of the dry rivers which cut the syncline.
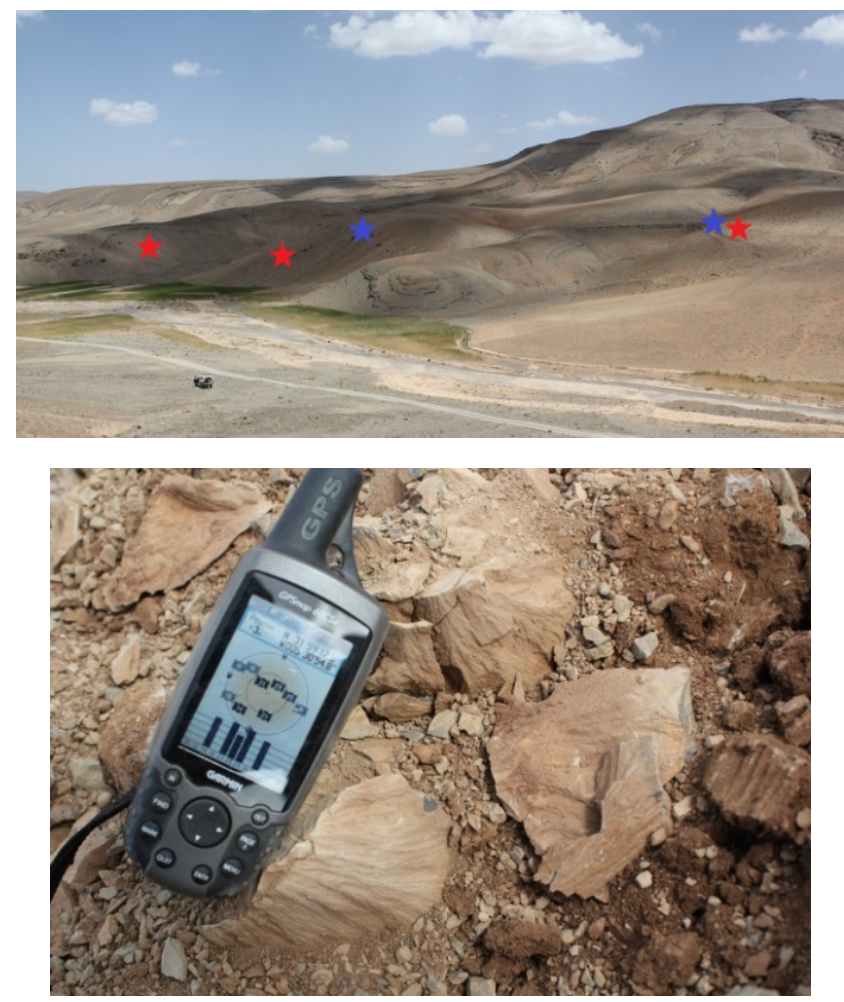

Figure 3. Agoudal crater (red stars: shatter cones; bleu stars: impact breccias)and shatter cones in quaternary deposits

\subsection{Meteorite}

The mapping of the locations, where the fragments of the meteorite were found, showed us that the fireball exploded into thousands of fragments that are scattered on a field with a north-south direction and about $38 \mathrm{~km}$ long, which would be the direction of the strewn field [9]. North of lake Isli the meteorite occurs only in small millimeter- to centimeter-sized fragments included in breccias or in small veins of silicate liquid. The Agoudal area at the south, where the maximum of the samples were collected, is a desert area, relatively flat and was dotted with hundreds of meteorites that were collected since 2007. More than a ton of specimens were collected over a period of 6 years. Some sources speculate that even a still bigger quantity had been recovered (up to 2 tons) but there is no way to make an accurate estimate. Due to the continuing intense exploration specimens are still found. The fragments weight from 1 gram to $196 \mathrm{~kg}$.

The members of the laboratory collected many fragments 
of Central High Atlas meteorite at the GPS coordinates Agoudal ( $31^{\circ} 59^{\prime} 08.0^{\prime \prime} \mathrm{N}$; $\left.05^{\circ} 31^{\prime} 00.6^{\prime \prime} \mathrm{W}\right), \operatorname{Akdim}\left(32^{\circ} 04^{\prime}\right.$ $\left.00.5^{\prime \prime} \mathrm{N} ; 05^{\circ} 28^{\prime} 57.3^{\prime \prime} \mathrm{W}\right)$, Bouzmou ( $32^{\circ} 05^{\prime} 35.9^{\prime \prime} \mathrm{N} ; 05^{\circ}$ $32^{\prime} 12.0^{\prime \prime} \mathrm{W}$ ) and Tighdouine ( $32^{\circ} 13^{\prime} 04.2^{\prime \prime} \mathrm{N}$; $05^{\circ} 26^{\prime} 42.3^{\prime \prime}$ $\mathrm{W})$. All the specimens collected at different places in the region of in Central High Atlas have the same chemical composition and even the same mineralogical characteristics of a IIAB iron meteorite [9].

The presence of meteorite specimens in the Soltanian sediments [3] indicates that the fall of the meteorite must have taken place about 40.000 years ago [10].

This age is consistent with the age of the oldest sediments of Isli lake [5].
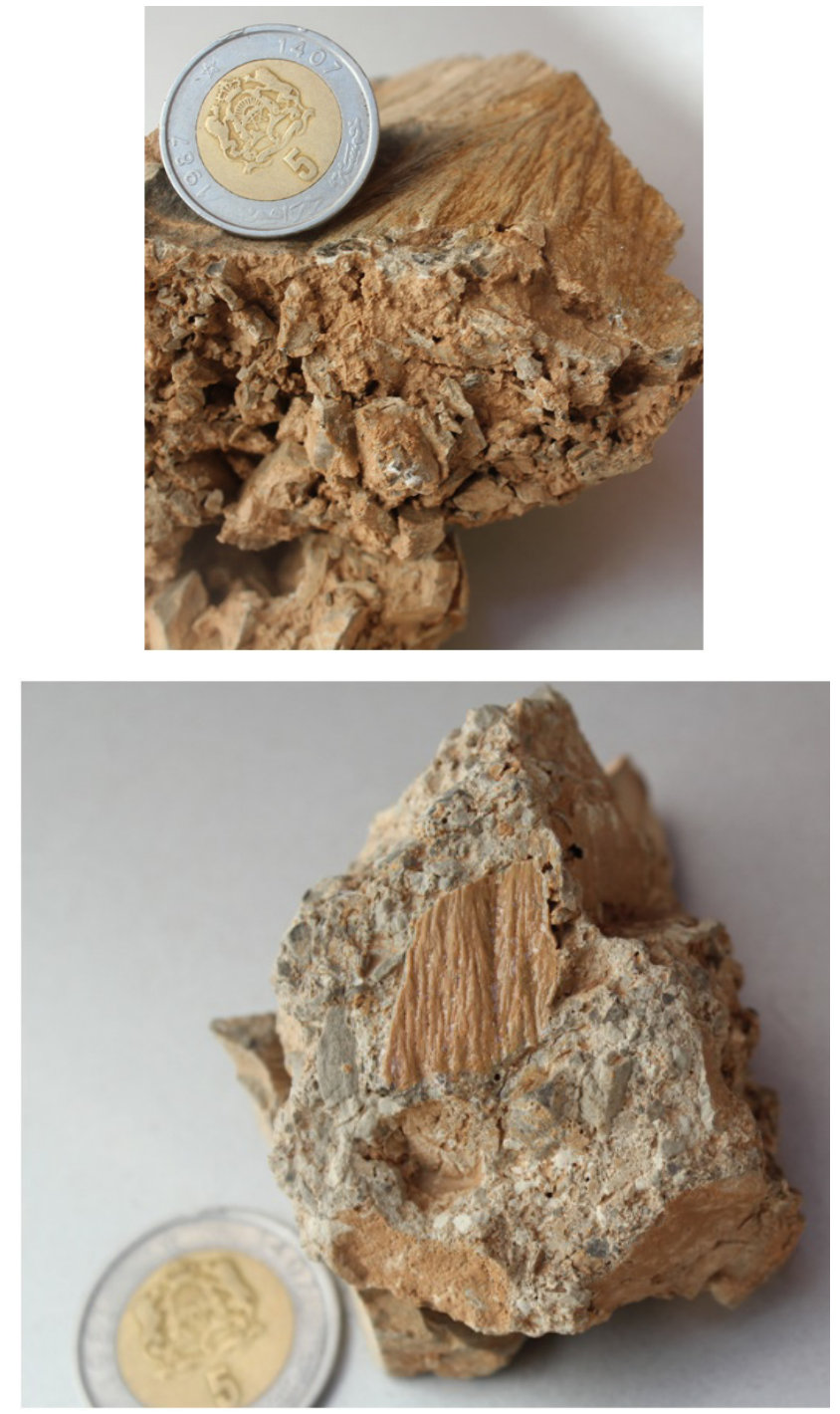

Figure 4. Shatter cones in the breccias

\subsection{Shatter Cones}

Shatter cones are common and extremely well developed in Agoudal area. They were first recognized by [2] and are bets developed in fine-grained carbonate lithologies. They have been found in samples of Jurassic limestone wrapped in quaternary deposits; they are also occur widely within marl fragments of the breccia from the main outcrop [2] and this work (Figure 4). The excellent preservation state and exposure at Agoudal allow a detailed study of the shatter cone distribution and morphology to be conducted.

The figure 5a shows characteristic structures in "Horsetail" produced by the shock wave of the impact [11]. Indeed, the Agoudal limestone presents different series of cones in a row with angles of $60^{\circ}$ for each series. They display many of the characteristics typical of shatter cones from other impact sites (striated surfaces, horsetail structures). The formation of such features can be explained by models of Baratoux and Melosh [12] and Sagy et al. $[8,13]$. In the Baratoux and Melosh model, conical and complete cones result from conical tensile fractures that are produced by the interference of scattered elastic wave heterogeneities in the target rock.

The important results of our shatter cones observations from Agoudal are (1) found in quaternary deposits and within fragments of the breccias. (2) Apical angles range up to $60^{\circ}$. (3) While many shatter cones displayed curved, oblate, spoon-like surfaces [8] (figure 5b, 5d and 5e), many are also conical (figure 5c). (4) Shatter cones with apices pointing in opposite directions (figure 5f). (5) Complete Cones are present in $10-15 \%$ of the samples studied.

\section{Discussion and Conclusion}

Several models have been proposed for the formation of shatter cones. Johnson and Talbot [14] suggested that shatter cones form due to the interaction between a propagating shock wave and heterogeneities within the target rocks. Other workers have suggested that shatter cones are tensile fractures that form due to interference between the incident shock wave and the reflected stress waves [15]. However, Sagy et al. $[8,13]$, prefer a model in which shatter cones are fractures produced by nonlinear waves that propagate along a fracture front. In the outcrop studied possessed shatter cones with apices pointing in multiple directions, sometimes in completely opposite directions. This is in keeping with observations from other terrestrial craters [16] and is not explained by current models for shatter cone formation [15]. 

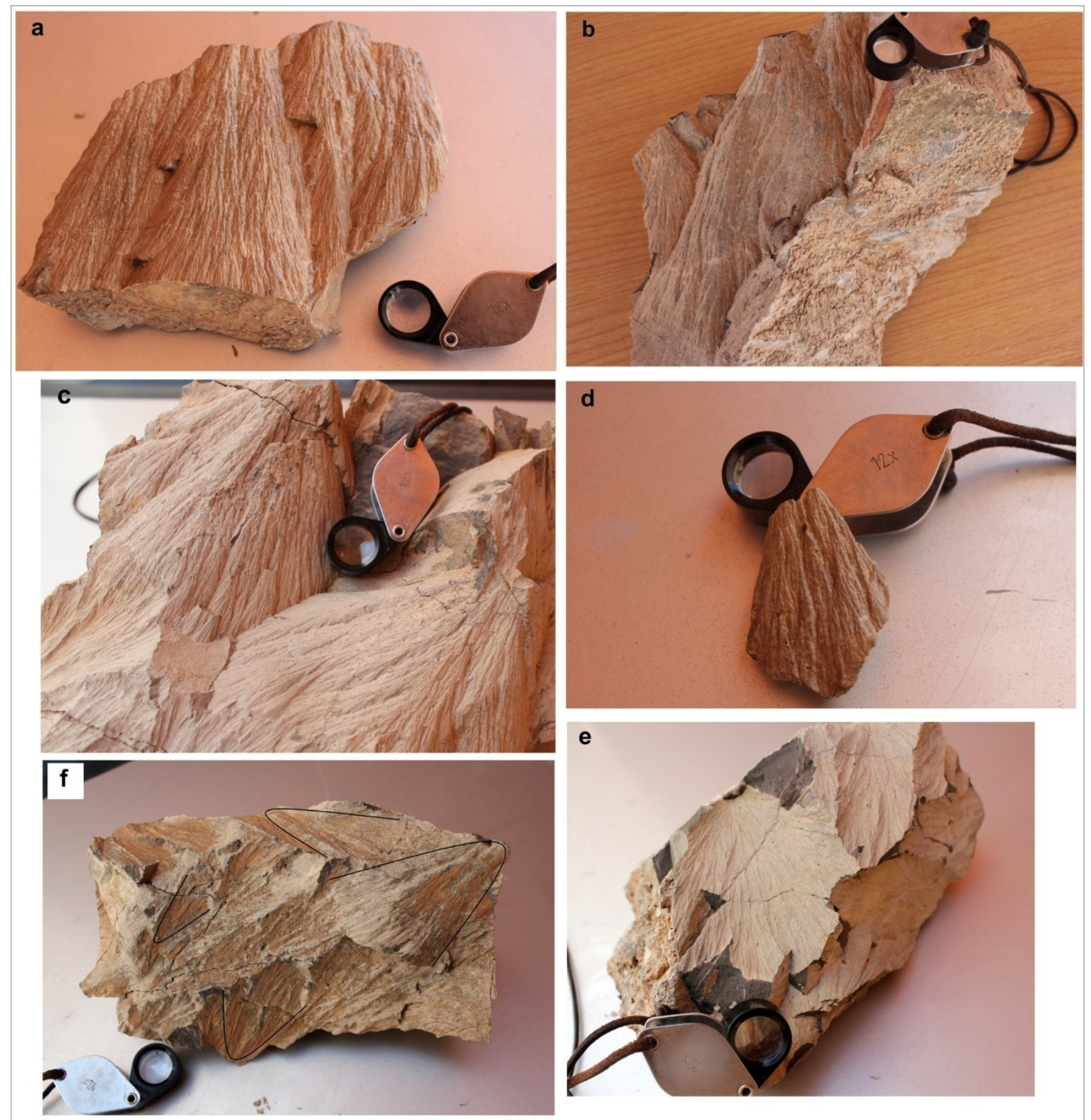

Figure 5. Hand specimen photographs of carbonate clasts with well developed shatter cones from Agoudal. (a) A well developed shatter cone $\sim 15 \mathrm{~cm}$ in diameter. (b) Two complete curving cones. (c) A well developed conical shatter cones. (d, e) oblate and spoon-like surface shatter cones. (f) Shatter cones with apices pointing in opposite directions.

The beautiful shatter cones have been found in samples of Jurassic limestone wrapped in quaternary deposits, predominantly at the flanks of the dry rivers; they are not observed in the bedrock [2]. These observations can be explained by two phenomena:

There really is a small impact crater in this region and that it has been laterally eroded.

Shatter cones are not in place; they are ejected from another impact crater, and transported, like the Isli crater that lies to the north. Moreover, Shatter cones occur widely within marl fragments of the breccia from the main outcrop

[2], and the region where the chatter cones corresponds to a large delta river of a north-south direction. This phenomenon has been observed in three craters identified in the world, the shatter cones at Vrederfort impact crater (located in the Free State of South Africa) are found at distances ranging from $10-60 \mathrm{~km}$ from the center of the crater [17]; the distribution of shatter cones in the Haughton impact structure, Canada shows that the shatter cones are found within ejecta blocks. As for the Ries crater shatter cones, in western Bavaria, Germany, we note that they are not only found in crystalline rocks exposed within the crater but can be sampled also as 
nice specimens from the Bunte breccia ejecta. These are, probably, the same conditions as obviously fulfilled at Isli Lake.

In conclusion, the shatter cones found in a small eroded impact crater at about $20 \mathrm{~km}$ to the south of Isli, are not in place because they were harvested in Jurassic limestone and wrapped in quaternary deposits, predominantly at the flanks of the dry rivers, they have not been observed in the bedrock. At $20 \mathrm{~km}$ north of the site of shatter cones, our team has demonstrated an impact crater $1.5 \mathrm{~km}$ in diameter $[1,9]$. So, we do believe that these shatter cones are produced at the time of formation of the Isli impact crater, and then have been ejected or transported by a large delta river of a north-south direction. The shatter cones were developed in the very beginning of the cratering process on passage of the shock wave and are then ejected with the shocked rocks. This hypothesis deserves to be supported by further studies.

\section{Acknowledgments}

We want to thank Bassou moulay Ali, Assou Baadich, Ainouch Mohamed and Outouch moha for their assistance in the collection of information. I also, we want to thank Professor Vaccaro caemela (University of Ferrara, Italy) and Professor Abia El Hassan (Ibn Zohr University, Morocco) for help and discussions.

\section{REFERENCES}

[1] A. Ibhi, H. Nachit, E. Abia, A. Ait Touchnt, C. Vaccaro. Isli and Tislit: The First Dual Impact Crater Discovered in Morocco. International Journal of Astronomy and Astrophysics, Vol. 3, No. 2A, 1-4, 2013.

[2] D. A. Sadilenko, C. A. Lorenz, M. A. Ivanova, I. A. Roshina, A. V. Korochantsev. A new small impact crater in the High Atlas, in the Agoudaliron strewnfield. 76th Annual Meteoritical Society Meeting \#5215, 2013.

[3] R. S. Dietz. Shatter cones in cryptoexplosion structures. BM French, NM Short (Ed.), Shock Metamorphism of Natural Materials, MD Mono Book Corp, Baltimore, Md, 267-285, 1968.

[4] D. J. Milton. Shatter cones-An outstanding problem in shock mechanics. In: D. J. Roddy, R. O. Pepin, R. B. Merrill, (Ed.), Impact and explosion cratering: New York, Pergamon Press,
703-714. 1977

[5] E. Zeroual. Enregistrements climatiques dans les sédiments de lac Isli (Haut Atlas, Maroc). Thesis, Cadi Ayyad University, Morocco, 230 pages, 1995.

[6] D. Stöeffler, F. Langenhorst. Shock metamorphism of quartz in nature and experiment: I. Basic observations and theory. Meteoritics \& Planetary Science, Vol. 29, 155-181, 1994.

[7] R. A. F. Grieve, F. Langenhorst, D. Stöffler. Shock metamorphism of quartz in nature and experiment. Meteoritics \& Planetary Science, Vol. 31, 6-35, 1996.

[8] A. Sagy, Z. Reches, J. Fineberg. Dynamic fracture by large extraterrestrial impacts as the origin of shatter cones. Nature, Vol. 418, 310-313, 2002.

[9] H. Nachit, A. Ibhi, C. Vaccaro. The Imilchil meteorite strewn field and Isli-Agoudal craters. International Letters of Chemistry, Physics and Astronomy, Vol. 11, 65-71, 2013.

[10] A. Weisrock, M. Fontugne. Morphogenèse éolienne littorale au Pléistocene supérieur et à l'Holocène dans l'Oulja atlantique marocaine. Quaternaire, Vol. 3, 164-175, 1991.

[11] D. E. Roach, A. D. Fowler, W. K. Fyson. Fractal fingerprinting of joint and shatter-cone surfaces, Geology, Vol. 21, No.8, 759-762, 1993.

[12] D. Baratoux, H. J. Melosh. The formation of shatter cones by shock wave interference during impacting. Earth and Planetary Science Letters, Vol. 216, 43-54, 2003.

[13] A. Sagy, J. Fineberg, Z. Reches. Shatter cones: Branched, rapid fractures formed by shock impactShatter cones. Journal of Geophysical Research, Vol. 109, 1-20, 2004.

[14] G. P. Johnson, R. J. Talbot. A theoretical study of the shock wave origin of shatter cones, Air Force Institute of Technology M.S. Thesis, Wright-Patterson AFB, Ohio, GSF/Mech 64-35, 92 pages, 1964.

[15] P. J. S. Gash. Dynamic mechanism for the formation of shatter cones. Nature, Vol. 230, 32-35, 1971.

[16] F. Wieland, W. U.Reimold, R. L. Gibson. New observations of shatter cones in the Vredefort impact structure, South Africa, and evaluation of current hypotheses for shatter cone formation. Meteoritics and Planetary Science, Vol. 41, No.11, 1737-1759, 2006.

[17] D. Baratoux, J. Melosh, U. Reimold. https:/www.cps-jp.org/seminar/fy2009/2009-128/baratoux/pub/Shattercones_Kobe.pdf, 2009. 